\title{
Review
}

\section{Pulmonary Hypertension in Idiopathic Pulmonary Fibrosis: A Review}

\author{
Georgia Pitsiou $^{\mathrm{a}}$ Despina Papakosta $^{\mathrm{a}}$ Demosthenes Bouros $^{\mathrm{b}}$ \\ a Department of Pneumonology, Aristotle University of Thessaloniki, G. Papanikolaou Hospital, Thessaloniki, and \\ ${ }^{b}$ Department of Pneumonology, Democritus University of Thrace, Alexandroupolis, Greece
}

\author{
Key Words \\ Idiopathic pulmonary fibrosis • Pulmonary hypertension • \\ Pulmonary function tests - Six-minute walk test • \\ Echocardiography
}

\begin{abstract}
Idiopathic pulmonary fibrosis (IPF) is a progressive diffuse parenchymal disease with a poor prognosis. Pulmonary hypertension (PH) often complicates the course of IPF and may even be found in patients with preserved lung function. Possible pathogenetic mechanisms of PH in IPF include vascular destruction, pulmonary hypoxic vasoconstriction and vascular remodeling due to overexpression of cytokines and growth factors. PH in IPF patients is associated with decreased exercise capacity and a worse prognosis. Due to its prognostic significance, it seems important to investigate for $\mathrm{PH}$ in these patients. As the symptoms of $\mathrm{PH}$ in IPF are nonspecific, the development of $\mathrm{PH}$ in a patient with known IPF can be easily overlooked. Noninvasive methods provide clues for the diagnosis, but their sensitivity is limited. Doppler echocardiography is a useful tool for the detection of $\mathrm{PH}$ which also provides additional information regarding associated cardiac abnormalities. However, right heart catheterization remains the gold standard diagnostic test. Therapeutic options for $\mathrm{PH}$ in IPF are limited. Long-term oxygen administration for the correction of hypoxemia should be recommended. The availability of new pharmacological agents in the treatment of $\mathrm{PH}$ has raised the possibility of
\end{abstract}

therapy in patients with IPF and associated $\mathrm{PH}$. Whether these $\mathrm{PH}$-targeted therapies may be of benefit in this patient group, in terms of improving functional outcomes and survival, remains uncertain.

Copyright $\odot 2011$ S. Karger AG, Basel

\section{Introduction}

Idiopathic pulmonary fibrosis (IPF) is a chronic fibrosing and progressive parenchymal lung disease of unknown etiology limited to the lung $[1,2]$. IPF is the most common idiopathic interstitial pneumonia with a remarkable diversity of prevalence by country, ranging from 14 to 20 per 100,000 inhabitants [3-5]. It is a fatal disorder with a median survival of $2.5-5$ years, as no effective treatment exists to date. Poor prognosis has been associated with older age, male gender, lower forced vital capacity, lower diffusing capacity, desaturation during exercise and the extent of fibrosis on imaging studies [68]. Pulmonary hypertension $(\mathrm{PH})$ is recognized as a severe complication of IPF $[6,9]$. The development of $\mathrm{PH}$ during the course of the disease has a negative impact on the functional status and quality of life of IPF patients and is associated with poor survival [10-13]. The approval of new drugs for the treatment of pulmonary arterial hypertension (PAH) has renewed interest in IPF and associated $\mathrm{PH}$ and raised the possibility of therapeutic intervention for these patients.

\section{KARGER}

Fax +4161306 1234

E-Mail karger@karger.ch

www.karger.com
(C) $2011 \mathrm{~S}$. Karger AG, Basel

$0025-7931 / 11 / 0823-0294 \$ 38.00 / 0$

Accessible online at:

www.karger.com/res
Demosthenes Bouros, MD, PhD, FCCP

Department of Pneumonology, Democritus University of Thrace

University Hospital of Alexandroupolis

GR-68100 Alexandroupolis (Greece)

Tel. +30 25510 76105, E-Mail bouros@med.duth.gr 
The present review attempts to explore the role of $\mathrm{PH}$ in IPF and summarizes the current knowledge about the epidemiology, pathogenesis, diagnosis, prognostic significance and possible treatment for this condition.

\section{Definition and Epidemiology}

The recent guidelines for the diagnosis and treatment of $\mathrm{PH}$ [14] classifies $\mathrm{PH}$ in IPF in the third group of 'PH due to lung diseases and/or hypoxia', differentiating this from the other clinical conditions causing $\mathrm{PH}$. Based on the same guidelines, $\mathrm{PH}$ has been defined as an increase in mean pulmonary arterial pressure (mPAP) of $\geq 25$ $\mathrm{mm} \mathrm{Hg}$ at rest as assessed by right heart catheterization (RHC). At the present time, the definition for $\mathrm{PH}$ upon exercise as assessed by RHC is not supported by the guidelines due to the lack of published data. Another point concerning $\mathrm{PH}$ associated with lung disease is the definition of 'out of proportion' $\mathrm{PH}$. The current guidelines use the criterion of $\mathrm{mPAP} \geq 40-45 \mathrm{~mm} \mathrm{Hg}$ for the definition of 'out of proportion' $\mathrm{PH}$ in chronic lung diseases, but whether this threshold value is suitable for patients with IPF is not clear [14].

Despite its critical role, the epidemiology of PH in IPF has not been extensively studied, and the reported incidence is wide, ranging from 32 to $84 \%[10,11]$. Several factors account for this wide range in the prevalence of $\mathrm{PH}$ in IPF. First is the inclusion of both incident and prevalent cases in the studies. Patients in whom the diagnosis has been made several months or years ago are more likely to have advanced disease and theoretically more likely to have $\mathrm{PH}$. Second is the method used for the diagnosis. RHC remains the gold standard for hemodynamic evaluation of pulmonary circulation, but it is an invasive procedure and impractical to perform in a serial fashion. On the other hand, transthoracic echocardiography (TTE) is a useful modality for the detection of $\mathrm{PH}$; it is noninvasive, repeatable and convenient to perform in daily clinical practice, but its accuracy for the assessment of $\mathrm{PH}$ in IPF patients has been seriously questioned $[15,16]$. Furthermore, when evaluated at an earlier stage of the disease, IPF patients may show normal hemodynamics at rest and develop significant $\mathrm{PH}$ only during exercise $[17,18]$. Finally, the majority of data regarding the incidence of $\mathrm{PH}$ in IPF comes from selected cohorts of patients, mostly with advanced disease, undergoing evaluation for lung transplantation for whom RHC data are usually available.

Three studies have reviewed data from lung transplant registries. In a large retrospective analysis of RHC data from the lung transplant registry of the US, $\mathrm{PH}$ was common in IPF patients awaiting lung transplantation; $46.1 \%$ of the subjects presented $\mathrm{PH}$, defined as $\mathrm{mPAP} \geq 25 \mathrm{~mm}$ $\mathrm{Hg}$, and almost $9 \%$ had severe $\mathrm{PH}$, defined as $\mathrm{mPAP} \geq 40$ $\mathrm{mm} \mathrm{Hg}$ [19]. Variables independently associated with the presence of $\mathrm{PH}$ were the need for supplemental oxygen and the presence of elevated wedge pressure and forced expiratory volume in $1 \mathrm{~s}$. In another analysis of data from the United Network for Organ Sharing between 2004 and 2005, 454 patients with IPF listed for lung transplantation were retrospectively studied. $\mathrm{PH}$, defined as mPAP $\geq 25$ $\mathrm{mm} \mathrm{Hg}$, was detected in $36 \%$ of the 376 patients who underwent RHC [20]. Finally, in a recent retrospective review of data of 626 lung-transplanted patients, $\mathrm{PH}$ confirmed with RHC was found in $43 \%$ of patients with a diagnosis of IPF (mPAP $33 \pm 8 \mathrm{~mm} \mathrm{Hg}$, range $26-57 \mathrm{~mm}$ $\mathrm{Hg})[21]$.

Other studies also report variable estimates of the frequency of PH in IPF patients. Nadrous et al. [11] used TTE to diagnose $\mathrm{PH}$, defined as estimated right ventricular systolic pressure (RVSP) $>35 \mathrm{~mm} \mathrm{Hg}$ at rest, in $84 \%$ of IPF patients who were evaluated at initial admission to a tertiary care referral medical center. Similarly, in a previous study we performed, we used TTE to screen for PH in a large cohort of 127 IPF patients at their initial admission to referral centers. Although the patients presented with varying impairment of functional status, increased estimated RVSP was present in more than half $(55 \%)$ of our patients [22].

Other studies have used invasive hemodynamics for the estimation of the prevalence of PH in IPF patients. Lettieri et al. [10] retrospectively reviewed data from a cohort of patients with IPF who underwent RHC as part of an evaluation for lung transplantation. From a total of 79 patients, $\mathrm{PH}$, defined as $\mathrm{mPAP}>25 \mathrm{~mm} \mathrm{Hg}$, was present in 25 patients (31.6\%). The presence of $\mathrm{PH}$ was associated with a lower diffusing capacity of the lung for carbon monoxide $\left(\mathrm{D}_{\mathrm{LCO}}\right)$ and the use of supplemental oxygen therapy. Moreover, in a retrospective review of the RHC and pulmonary function test (PFT) data of 118 IPF patients seen at a tertiary referral center over an 8 -year period, $\mathrm{PH}$ was noted in 48 patients (40.7\%) [23]. Cardiac dysfunction might have played a role in this estimation, since $16.1 \%$ of the patients had an associated elevated pulmonary capillary wedge pressure. Finally, Nathan et al. [24], analyzing serial RHC data, showed progressive development of $\mathrm{PH}$ in patients with advanced IPF who were transplant candidates. $\mathrm{PH}$ was found in $38.6 \%$ of the patients at baseline, while at the time of transplant, $86.4 \%$ of the patients demonstrated $\mathrm{PH}$. 


\section{Pathogenesis}

The pathogenesis of PH in IPF is incompletely understood. Multiple diverse mechanisms are implicated in the development of PH such as vascular obstruction or destruction from progressive parenchymal fibrosis, pulmonary hypoxic vasoconstriction and vascular remodeling due to overexpression of cytokines and growth factors $[25,26]$.

The destruction of the pulmonary capillary bed by fibrotic tissue is an initial mechanism. Vessel ablation in areas of dense fibrosis and within fibroblastic foci contributes to overall reduction of vessel density and elevated pulmonary vascular resistance [27]. However, lack of close association between restrictive physiology and $\mathrm{PH}$ supports the hypothesis that factors other than fibrosis and progressive reduction in vasculature are involved in the development of PH in IPF [10-12]. A recent study demonstrated that iron deposition and alveolar septal capillary density, histologic features associated with postcapillary remodeling, were associated with RVSP, suggesting that these features are possible morphologic predictors of PH in IPF [28].

Furthermore, an imbalance between angiogenesis and angiostasis may underlie the pathogenesis of IPF-associated $\mathrm{PH}$ [25]. The existence of neovascularization in IPF was first described in 1963 by Turner-Warwick [29]. Other studies reported increased capillary density and angiogenesis in nonfibrotic lung tissues [27, 30-32]. However, the new vessels formed in fibrotic areas are abnormal and are characterized by the absence of an elastin layer, which may contribute further to the development of $\mathrm{PH}$ [27]. The role of capillary regression and proliferation and the resultant effect on $\mathrm{PH}$ is still unclear and needs to be further clarified.

Endothelial dysfunction may represent another mechanism accounting for the development of $\mathrm{PH}$ in IPF. Gagermeier et al. [33] suggested an abnormal vascular phenotype in a subgroup of IPF patients presenting moderate to severe $\mathrm{PH}$. Using gene microarray analysis, a subset of differentially expressed genes was identified. A decrease in angiogenic factors such as vascular endothelial growth factor and platelet endothelial cell adhesion molecule as well as an increase in inflammatory and remodeling genes such as the phospholipase $\mathrm{A}_{2}$ gene was observed. This fact suggests an alteration in the vascular cell phenotype in IPF patients that may contribute to the development of $\mathrm{PH}$ [33].

Hypoxic pulmonary vasoconstriction leading to permanent medial hypertrophy is a well-recognized mecha- nism of PH in chronic lung disease [34]. Pulmonary vascular remodeling is more than just medial hypertrophy from long-lasting hypoxic vasoconstriction; all layers of the vessel wall appear to be involved, with intimal changes being the most prominent [34]. Undoubtedly, this mechanism plays a role, but it is unlikely to account for all cases of $\mathrm{PH}$, for example the presence of $\mathrm{PH}$ in normoxemic IPF patients. Furthermore, intermittent nocturnal hypoxia and also exercise-induced desaturation, which are often present in IPF patients $[8,35]$, might represent important factors in the development of disproportionate $\mathrm{PH}$ in these patients and need to be appropriately evaluated [36]. Interestingly, Pouwels-Fry et al. [37] demonstrated that oxygen did not improve an exerciseinduced increase in pulmonary artery pressure in IPF patients, suggesting that hypoxic vasoconstriction is not the only mechanism contributing to the acute increase in pulmonary pressure during exercise.

Several mediators have been implicated in the pathogenesis of both IPF and idiopathic PAH $[25,38]$. This fact suggests possible common mechanistic pathways in the two disorders but also provides possible therapeutic targets. Profibrogenic leukotrienes are overproduced in both diseases due to upregulation of 5-lipoxygenase [39, 40]. Leukotrienes, in turn, may upregulate mediators such as tumor necrosis factor- $\alpha$, platelet-derived growth factor and fibroblast growth factor, all of which are involved in both pulmonary vascular remodeling and lung fibrosis. Furthermore, prostaglandin $\mathrm{E}_{2}$ levels have been reported to be reduced in bronchoalveolar lavage fluid of IPF patients [39], while there is evidence of decreased prostacyclin synthase expression in pulmonary vessels of patients with idiopathic PAH [41]. Decreased levels of prostaglandin $\mathrm{E}_{2}$ may lead to increased expression of tumor necrosis factor- $\alpha$ and transforming growth factor- $\beta$, both of which are involved in interstitial collagen deposition and pulmonary artery remodeling [25].

Endothelin-1 (ET-1) is a powerful vasoconstrictor and also a mitogen that stimulates the proliferation of smooth muscle cells [42]. ET-1 may also participate in the pathogenesis of lung fibrosis through its effects on cellular apoptosis and the oxidant/antioxidant imbalance [43]. The molecule exerts its effects by binding to 2 distinct receptor isoforms in pulmonary vascular smooth muscle cells, i.e. endothelin A and endothelin B receptors. In patients with idiopathic PAH, enhanced expression of ET-1 was detected in plexiform lesions [44]. Elevated serum levels of ET-1 have been detected in patients with IPF as well [45]. Increased concentrations of ET-1 in bronchoalveolar lavage fluid and secretion of ET-1 from alveolar 
macrophages have been reported in IPF and other pulmonary diseases [46]. Moreover, IPF lung tissue shows increased expression of the enzyme responsible for converting ET-1 [47], while arterial ET-1 levels were shown to correlate inversely with arterial oxygen and directly with mPAP in IPF patients [35].

\section{Diagnosis}

The symptoms of PH in IPF are nonspecific and include breathlessness, fatigue, weakness, palpitations and chest discomfort or syncope $[14,48]$. Exercise limitation is one of the first manifestations at earlier stages. Physical signs such as an accentuated pulmonary component of the second heart sound, pansystolic murmur of tricuspid regurgitation, fixed split of the second heart sound and murmur of pulmonary insufficiency may be present. Signs such as jugular vein distension, hepatomegaly and peripheral edema characterize more advanced cases as right ventricular dysfunction worsens.

As symptoms in both IPF and PH overlap widely, the development of $\mathrm{PH}$ in a patient with known IPF can be easily overlooked. A high index of clinical suspicion is thus required for the diagnosis. Clinicians should pursue further diagnostic testing for $\mathrm{PH}$ when the patient presents symptoms which are disproportionate to the severity of parenchymal lung disease.

Besides, several comorbidities such as obstructive sleep apnea, coronary artery disease with left ventricular dysfunction and pulmonary embolism, which are common in IPF patients, may contribute to the development of $\mathrm{PH}$ in this patient population $[49,50]$. Diagnostic testing is indicated not only for the establishment of a diagnosis of $\mathrm{PH}$ but also for differential diagnosis and for the exclusion of other causes of $\mathrm{PH}$ in patients with IPF.

\section{Imaging}

Findings of central pulmonary arterial dilatation, loss of the peripheral blood vessels and right ventricular enlargement on chest X-ray suggest the presence of $\mathrm{PH}$. In general, the degree of $\mathrm{PH}$ does not correlate with the extent of radiographic abnormalities [14]. On computed tomography (CT), enlargement of the main pulmonary artery $(>29 \mathrm{~mm})$, right ventricular dilatation and an increased diameter of the pulmonary artery as compared with the aorta are indicative of the development of $\mathrm{PH}$ [51]. However, in a recent study, high-resolution chest CT findings failed to predict the presence of $\mathrm{PH}$ in advanced IPF [52]. High-resolution CT may also provide clues as to alternative etiologies of $\mathrm{PH}$ such as pulmonary venoocclusive disease, which can be mistaken for IPF complicated by $\mathrm{PH}$ [53].

\section{Electrocardiogram}

An electrocardiogram (ECG) may provide supportive evidence of $\mathrm{PH}$ by demonstrating right ventricular hypertrophy and strain and right atrial dilatation. The ECG has insufficient sensitivity (55\%) and specificity (70\%) to be a screening tool for detecting significant $\mathrm{PH}$ [14]. Consequently, absence of the above ECG findings does not exclude the presence of $\mathrm{PH}$.

\section{Pulmonary Function Tests}

PFTs and arterial blood gases are necessary to identify the contribution of parenchymal lung disease. Interestingly, a poor association between $\mathrm{PH}$ and pulmonary function has been found in several studies [10-12, 23, 54]. Lettieri et al. [10] did not find a significant difference in lung function indexes, except for $\mathrm{D}_{\mathrm{LCO}}$, between IPF patients with and without $\mathrm{PH}$. The combination of a $\mathrm{D}_{\mathrm{LCO}}$ of $<40 \%$ predicted and the need for supplemental oxygen determined in subjects with a resting $\mathrm{SpO}_{2}<88 \%$ identified the presence of $\mathrm{PH}$ with a sensitivity and specificity of 65 and $94.1 \%$, respectively. Similarly, in the study of Nadrous et al. [11], none of the lung function tests correlated with estimated RVSP, with the exception of $\mathrm{D}_{\mathrm{LCO}}$, to which RVSP was inversely related. More recently, Nathan et al. [23] failed to demonstrate a significant relationship between measures of lung volumes with underlying $\mathrm{PH}$, whereas a modest association was found between $\mathrm{D}_{\mathrm{LCO}}$ and $\mathrm{PH}$, with $\mathrm{D}_{\mathrm{LCO}}<30 \%$ predicted associated with a twofold higher prevalence of $\mathrm{PH}$.

Zisman et al. $[55,56]$ developed a method to screen for $\mathrm{PH}$ based on a formula to predict mPAP from standard lung function tests. In this equation, resting room air pulse oximetry $\left(\mathrm{SpO}_{2}\right)$ together with percentage forced vital capacity and $\mathrm{D}_{\mathrm{LCO}} \%$ predicted were found to be important indices for the calculation of pulmonary pressure. Although the formula has a low positive predictive value of only $51 \%$, it provides a high negative predictive value of $96 \%$, thus identifying patients with IPF that have a low risk of $\mathrm{PH}$. A recent evaluation of this formula showed that it is a useful tool which can be used like TTE to screen for PH in IPF patients [57].

The development of $\mathrm{PH}$ is common in combined pulmonary fibrosis and emphysema syndrome [58-60]. This could be considered a distinct entity with a characteristic functional profile, with preserved lung volumes, strongly impaired $\mathrm{D}_{\mathrm{LCO}}$ and hypoxemia upon exercise [61]. The 
severe impairment of diffusion capacity probably represents the additive or synergistic effects of emphysema, fibrosis and pulmonary vascular disease and is one of the hallmarks of the syndrome [62]. The associated high prevalence of $\mathrm{PH}$ is a critical determinant of poor prognosis [58-60].

\section{Exercise Capacity}

Assessment of exercise capacity is a key part of the evaluation of $\mathrm{PH}$. The most commonly used exercise tests are the 6-min walk test (6MWT) and cardiopulmonary exercise testing. Impaired gas exchange which worsens with exercise is a common feature in the pathophysiology of IPF and appears to have prognostic value as well $[7,8$, 63]. When PH is present in the setting of IPF, common physiological abnormalities during exercise include decreased maximal oxygen consumption, increased dead space with progressive exercise and a low anaerobic threshold [64, 65]. Importantly, left ventricular dysfunction, which is often present in these patients, could be an additional factor that may further impair exercise performance [66].

Exercise limitation disproportionate to lung volume abnormalities and prominent arterial oxygen desaturation during exercise should raise suspicion of the development of PH in IPF patients. This negative impact of $\mathrm{PH}$ on the exercise capacity of IPF patients has been shown in several studies; in a cohort of patients with interstitial lung diseases evaluated for lung transplantation with $\mathrm{RHC}$, patients with $\mathrm{PH}$ differed from those without $\mathrm{PH}$ in terms of distance walked and also minimal $\mathrm{SpO}_{2}$ upon exercise [67]. In the study by Lettieri et al. [10], both the distance walked and $\mathrm{SpO}_{2}$ at the end of the $6 \mathrm{MWT}$ were significantly lower in IPF patients with PH. Finally, in a study evaluating exercise intolerance in patients with pulmonary fibrosis via cardiopulmonary exercise testing, patients suffering from $\mathrm{PH}$ showed a significantly lower exercise capacity and worsened dyspnea, being more hypoxic both at rest and during exercise [13].

Gas exchange parameters and exercise desaturation seem to represent better indices than PFTs in characterizing $\mathrm{PH}$ in patients with IPF; in a recent study by Nathan et al. [16], the parameter from the 6MWT that best predicted $\mathrm{PH}$ was exercise desaturation. Specifically, desaturation to $<85 \%$ presented $100 \%$ sensitivity and $61.9 \%$ specificity for detecting underlying $\mathrm{PH}$. Furthermore, in another study, in a consecutive population of 81 patients with IPF who underwent cardiopulmonary exercise testing, resting RVSP was found to correlate significantly with exercise parameters indicative of gas exchange and circulatory impairment but not with defective lung mechanics [68].

\section{Transthoracic Echocardiography}

TTE is a useful, noninvasive tool for the detection of $\mathrm{PH}$. The estimation of pulmonary pressure is based on the peak velocity of the jet of tricuspid regurgitation using the simplified Bernoulli equation [69]. Tricuspid regurgitation velocity of $2.9-3.4 \mathrm{~m} / \mathrm{s}$, which corresponds to an estimated RVSP of $37-50 \mathrm{~mm} \mathrm{Hg}$, assuming a right atrial pressure of $5 \mathrm{~mm} \mathrm{Hg}$, is considered suggestive of $\mathrm{PH}$ [14]. Other echocardiographic variables that might raise suspicion of $\mathrm{PH}$ include a short acceleration time of right ventricular ejection, increased dimensions of right heart chambers, abnormal shape and function of the interventricular septum, increased right ventricular wall thickness and a dilated main pulmonary artery [14]. TTE can also provide additional information for associated abnormalities such as left ventricular systolic and diastolic dysfunction, valvular disease and pericardial effusion. Most studies report a strong correlation between Doppler echocardiography and pulmonary artery pressure assessed by RHC in IPF patients $[15,70]$. The reported sensitivity of TTE-estimated RVSP for detecting PH ranges from 0.79 to 1.00 and specificity from 0.60 to 0.98 [48]. However, there are significant limitations in the performance of TTE in patients with chronic lung disease $[15,16]$. In a cohort study of Arcasoy et al. [15] including 374 lung transplant candidates with advanced lung disease, estimation of RVSP by Doppler TTE was possible in less than one half (44\%) of all patients. A discordance of greater than $10 \mathrm{~mm} \mathrm{Hg}$ between estimated and measured RVSP was found in $52 \%$ of all patients. In addition, in the population with interstitial lung disease, the positive and negative predictive values of TTE were low when compared to RHC measures [15].

\section{Right Heart Catheterization}

RHC remains the gold standard method for the diagnosis of PH. It helps to establish the severity and etiology of $\mathrm{PH}$ and also to assess pulmonary vasoreactivity, thus giving useful information for guiding therapy and for prognosis [14]. When performed at experienced centers, RHC has low morbidity (1.1\%) and mortality rates $(0.055 \%)$ [71]. However, at this time, the indication to perform RHC in patients with $\mathrm{PH}$ associated with chronic lung disease is questionable since there is no clear indication for PH therapy [14]. RHC in advanced lung disease should be reserved for patients with suspected 'out of proportion' $\mathrm{PH}$ on TTE, for establishing a definite diagnosis 
Table 1. Key diagnostic symptoms and tests for diagnosis and differential diagnosis of PH in patients with IPF

\begin{tabular}{ll}
\hline History & dyspnea disproportionate to ventilatory restriction, palpitations, chest pain \\
\hline Physical examination & $\begin{array}{l}\text { accentuated pulmonary component of S2, jugular vein distension, } \\
\text { hepatomegaly, peripheral edema }\end{array}$ \\
\hline Chest X-ray & central pulmonary arterial dilatation, cardiomegaly \\
\hline CT chest angiography & $\begin{array}{l}\text { main PA }>29 \text { mm, diameter of PA/aorta }>1, \\
\text { exclusion of pulmonary embolism }\end{array}$ \\
\hline ECG & right ventricular hypertrophy and strain \\
\hline PFTs & reduction of D LCo disproportionate to lung volumes \\
\hline Arterial blood gases & low resting oxygen saturation, need for supplemental oxygen \\
\hline Overnight oximetry & assessment of oxygenation during sleep; exclusion of obstructive sleep apnea \\
\hline 6 MWT & low distance walked, significant exercise desaturation \\
\hline TTE & tricuspid regurgitation, increased dimensions of right heart chambers \\
\hline RHC & increased mPAP $(\geq 25$ mm Hg) with a low PWP $(\leq 15$ mm Hg) \\
\hline BNP, NT-proBNP & elevated levels \\
\hline Immunological markers & exclusion of connective tissue disease \\
\hline
\end{tabular}

$\mathrm{PA}=$ Pulmonary artery; $\mathrm{PWP}=$ pulmonary wedge pressure; $\mathrm{NT}$-proBNP = N-terminal prohormone BNP.

of $\mathrm{PH}$ in candidates for lung transplantation and also for patients presenting frequent episodes of right ventricular failure [14]. RHC might also be considered in IPF subjects with dyspnea insufficiently explained by lung mechanical disturbances, patients with low resting $\mathrm{SpO}_{2}$ who need supplemental oxygen therapy or present significant exercise desaturation and even in patients demonstrating a reduction of $\mathrm{D}_{\mathrm{LCO}}$ disproportionate to lung volumes $[38,72]$.

\section{Natriuretic Peptides}

Another approach to the diagnosis of PH in IPF patients is based on the measurement of natriuretic peptides. These are peptide hormones that are released from cardiac myocytes in response to cardiac pressure and volume overload [73]. Both B-type natriuretic peptide (BNP) and $\mathrm{N}$-terminal prohormone BNP can serve as prognostic markers and screening parameters for $\mathrm{PH}$ [74-78]. In the study of Leuchte et al. [75], elevated BNP concentrations identified significant $\mathrm{PH}$ with a sensitivity of 0.85 and a specificity of 0.88 and predicted mortality in patients with $\mathrm{PH}$ and chronic lung disease. Conversely, a normal plasma BNP concentration is associated with a very low probability of $\mathrm{PH}$ and prolonged survival [74,
75]. In a retrospective review of 131 patients with IPF, Song et al. [78] found that BNP performed better than estimated RVSP as a marker of prognosis. Similarly, in a population of patients with interstitial lung disease, an increased serum BNP concentration was shown to be the strongest predictor of overall mortality [79].

Moreover, BNP can serve as a noninvasive marker that reflects the severity of $\mathrm{PH}$; BNP concentration was shown to correlate significantly to hemodynamic measures, functional class and 6MWT distance [74]. However, BNP levels do not allow early diagnosis of mild or latent $\mathrm{PH}$, and elevated plasma levels seem to normalize in completely compensated disease despite the presence of $\mathrm{PH}$ [72]. Moreover, the diagnostic accuracy of N-terminal prohormone BNP is diminished by renal function since renal excretion is the main route of clearance for the molecule [76]. Finally, further studies focusing exclusively on patients with IPF are needed to validate this marker in this patient population [75].

Table 1 summarizes the key diagnostic factors from patient history and physical examination and also the tests for diagnosis and differential diagnosis of $\mathrm{PH}$ in patients with IPF. 


\section{Prognostic Significance}

The development of $\mathrm{PH}$ in IPF patients is associated with worse survival $[6,10-12,78,80,81]$. In an earlier prospective study in a cohort of 238 IPF patients, King et al. [6] showed that the presence of $\mathrm{PH}$ as estimated by the size of the pulmonary artery on chest X-ray correlated with mortality. More recently, in the study of Nadrous et al. [11], RVSP estimated by TTE had a significant adverse impact on survival; when patients were divided into 3 subgroups, i.e. RVSP $\leq 35 \mathrm{~mm} \mathrm{Hg}, 36-50 \mathrm{~mm} \mathrm{Hg}$ and $>50 \mathrm{~mm} \mathrm{Hg}$, the median survival rates for these 3 groups were $4.8,4.1$ and 0.7 years, respectively. Thus, those patients with RVSP $>50 \mathrm{~mm} \mathrm{Hg}$ had significantly worse survival compared to the other subgroups [11]. In the study of Lettieri et al. [10], in which RHC data were retrospectively analyzed, increasing $\mathrm{MPAP}$ was shown to be a significant predictor of death; 1-year mortality rates were higher among those subjects with $\mathrm{PH}$ (28.0 vs. 5.5\%, respectively; $\mathrm{p}=0.002$ ), while the presence of $\mathrm{PH}$ predicted mortality with a sensitivity and specificity of 57.1 and 79.3\%, respectively. Furthermore, Hamada et al. [12] prospectively analyzed data of 78 IPF patients undergoing initial workup with RHC and PFTs. Although the cutoff value of mPAP of $17 \mathrm{~mm} \mathrm{Hg}$ which was used does not fulfill the criterion for $\mathrm{PH}$, the authors demonstrated a significant difference in the 5 -year survival rate between the groups with normal (62.2\%) and high mPAP (16.7\%) [12]. In the same study, $\mathrm{D}_{\text {LCO }}$ was the only significant parameter to predict survival time [12].

Novel echocardiographic indices might prove useful for risk stratification in these patients before severe $\mathrm{PH}$ is established; in a study we performed in a small cohort of IPF patients with mild to moderate $\mathrm{PH}$, tissue Doppler parameters of right ventricular function were found to be strongly associated with the severity of $\mathrm{PH}$ and correlated better with survival than conventional TTE parameters [82]. Lastly, Swigris et al. [80] showed that heart rate recovery after the $6 \mathrm{MWT}$ predicts survival in IPF patients. In a multivariate model, the presence of estimated RVSP $>35 \mathrm{~mm} \mathrm{Hg}$ was a predictor of heart rate recovery $1 \mathrm{~min}$ after the 6MWT [80].

The impact of preoperative $\mathrm{PH}$ on the outcome of patients with advanced lung disease after lung transplantation is controversial [83-87]. However, in a cohort study of 830 IPF patients in the International Society for Heart and Lung Transplant Registry, elevated pulmonary artery pressure proved to be a risk factor for 90-day mortality after single-lung transplantation [87].

\section{Treatment}

Currently, there is no specific therapy for $\mathrm{PH}$ associated with IPF. The association of $\mathrm{PH}$ with reduced exercise capacity and excess mortality in IPF patients has suggested that specific $\mathrm{PH}$ therapies may be of benefit in this patient group [88]. However, published experience with specific $\mathrm{PH}$ drug therapy is limited. The current guidelines discourage the use of targeted $\mathrm{PH}$ therapies in $\mathrm{PH}$ associated with chronic lung disease since there are no systematic data regarding their safety or efficacy [14].

As hypoxemia is a potent pulmonary vasoconstrictor, correction of hypoxemia is a first priority. Long-term oxygen administration should be recommended to maintain arterial oxygen saturation above $90 \%$; however, the role of long-term oxygen therapy in the progression of $\mathrm{PH}$ in this patient group is less clear than in chronic obstructive pulmonary disease patients. Detection and correction of exertion-related oxygen desaturation should be performed as part of standard care, although in a small study, oxygen administration did not improve the exercise-induced increase in pulmonary artery pressure in IPF patients [37]. Screening for nocturnal hypoxemia may prove beneficial since nocturnal desaturation is a common finding in these patients [35, 49]. As an adjunct to conventional treatment, diuretics are indicated to manage volume overload due to right ventricular failure. Patients with right ventricular failure or low cardiac output may also benefit from digitalis.

There are 3 classes of $\mathrm{PH}$-targeted therapies approved for other groups of $\mathrm{PH}$ and in particular for $\mathrm{PAH}$ patients: prostacyclins, endothelin receptor antagonists and phosphodiesterase-5 inhibitors $[14,89,90]$. However, treatment with vasoactive agents in patients with lung fibrosis carries the risk of worsening hypoxemia due to the inhibition of hypoxic vasoconstriction in low-ventilation/ perfusion lung units [91-93].

Prostacyclin induces relaxation of vascular smooth muscle, inhibits the growth of smooth muscle cells and is also a powerful inhibitor of platelet aggregation with favorable effects in patients with PAH $[14,89]$. However, in patients with diffuse parenchymal lung disease, the use of intravenous prostacyclin has not proven beneficial because it lacks selectivity for the pulmonary vasculature $[91,93]$. Ghofrani et al. [93] compared the acute effects of epoprostenol, sildenafil and nitric oxide in 16 patients with PH secondary to lung fibrosis. All 3 agents reduced pulmonary vascular resistance, but in contrast to the others, prostacyclin increased the ventilation/perfusion mismatch and worsened gas exchange. 
Selective pulmonary vasodilatation by inhalation of a vasoactive agent is an appealing concept to circumvent the risk of a worsening ventilation/perfusion mismatch, which appears with systemic vasodilatory therapy. In a pilot study, Olschewski et al. compared the effects of intravenous prostacyclin, inhaled nitric oxide and aerosolized prostacyclin in 8 patients with lung fibrosis and associated PH [91]. Aerosolization of prostacyclin or its stable analog iloprost caused marked pulmonary vasodilatation with maintenance of gas exchange and systemic arterial pressure. In contrast, intravenous prostacyclin resulted in a significant drop in arterial pressure and worsening of hypoxemia [91].

Nevertheless, there are case reports of successful use of intravenous treprostinil, a prostacyclin analog, and inhaled nitric oxide as well as a bridge to lung transplantation in patients with IPF $[94,95]$.

Sildenafil is a potent and highly specific phosphodiesterase- 5 inhibitor with vasodilatory and antiproliferative effects approved for patients with PAH [96]. In the study by Ghofrani et al. [93], a single dose of sildenafil exerted its pulmonary vasodilatory effect while improving ventilation/perfusion matching. In contrast to infused prostacyclin, sildenafil showed selectivity for well-ventilated areas of the lung, resulting in an improvement rather than a deterioration in gas exchange [93]. In a preliminary report by Collard et al. [97], sildenafil improved 6MWT distance in a 3-month, open-label study which included 14 IPF patients with PH. Small uncontrolled studies have also reported sustained benefit with sildenafil in patients with secondary $\mathrm{PH}[98,99]$. However, in the Sildenafil Trial of Exercise Performance in IPF study, a placebocontrolled trial which included 180 patients with advanced IPF, the therapeutic efficacy of sildenafil was not established [100]. The study failed to show a benefit with sildenafil with regard to improvement of the 6MWT distance, which was the primary outcome. Nevertheless, sildenafil was associated with symptomatic improvement with regard to the degree of dyspnea and quality of life [100]. A certain limitation is that the study does not provide RHC data, which could have suggested the presence of a subgroup of patients with more severe pulmonary vascular disease.

Bosentan, an oral active dual endothelin A and endothelin $\mathrm{B}$ receptor antagonist, has been evaluated in $\mathrm{PAH}$ and has been shown to improve exercise capacity, functional class and hemodynamics in this patient group [101, 102]. In a small open-label study exploring the safety and tolerability of bosentan in 12 IPF patients, bosentan administration did not induce clinically relevant gas ex- change abnormalities as estimated by the multiple inert gas elimination technique [103]. Bosentan Use in Interstitial Lung Disease-1, a recent randomized placebo-controlled trial, investigated the role of bosentan in IPF [104]. The primary endpoint of improvement in 6-minute walk distance was not reached. There were trends towards delaying time to death or disease progression and improving quality of life. Observations from an exploratory analysis suggested benefits of bosentan with regard to quality of life and dyspnea in a subset of patients who had a diagnosis of IPF confirmed by surgical lung biopsy [105]. A prospective study is ongoing to assess the efficacy of bosentan in prolonging survival and time to disease progression in patients with biopsy-proven IPF.

Finally, lung transplantation should be considered in patients with severe or progressive disease despite medical therapy [106]. For patients with secondary $\mathrm{PH}$, no clear advantage was shown regarding the type of transplantation which should be performed, i.e. single versus double lung transplantation [107]. However, in the new Registry of the International Society for Heart and Lung Transplantation, double lung transplantation presents a higher relative risk for 1-year mortality compared to single lung transplantation for IPF patients [108].

\section{Conclusion}

In conclusion, $\mathrm{PH}$ is a common severe complication of IPF and is usually correlated with poor disease outcome and adverse impact on survival. As symptoms in IPF and $\mathrm{PH}$ overlap widely, the development of $\mathrm{PH}$ in a patient with known IPF can be easily overlooked. Clinicians should suspect $\mathrm{PH}$ and pursue further diagnostic testing for this condition when the patient's symptoms are disproportionate to the severity of the parenchymal lung disease and also when exercise limitation is disproportionate to lung volume abnormalities and prominent arterial oxygen desaturation occurs during exercise. RHC is the gold standard method for the diagnosis of $\mathrm{PH}$. Currently, there is no specific therapy for $\mathrm{PH}$ associated with IPF. As multiple diverse mechanisms not completely elucidated are implicated in the pathogenesis of PH in IPF, further understanding of pathogenetic pathways could probably optimize management of these patients. 


\section{References}

$>1$ American Thoracic Society/European Respiratory Society: International multidisciplinary consensus classification of the idiopathic interstitial pneumonias. Am J Respir Crit Care Med 2002;165:277-304.

$>2$ American Thoracic Society: Idiopathic pulmonary fibrosis: diagnosis and treatment. International Consensus Statement. Am J Respir Crit Care Med 2000;161:646-664.

3 Raghu C, Weycker D, Edelsberg J, et al: Incidence and prevalence of idiopathic pulmonary fibrosis Am J Respir Crit Care Med 2006;174:810-816.

$\checkmark 4$ Coultas DB, Zumwalt RE, Black WC, Sobonya RE: The epidemiology of interstitial lung diseases. Am J Respir Crit Care Med 1994;150:967-972.

$\checkmark 5$ Karakatsani A, Papakosta D, Rapti A, et al; Hellenic Interstitial Lung Diseases Group: Epidemiology of interstitial lung diseases in Greece. Respir Med 2009;103:1122-1129.

6 King TE Jr, Tooze JA, Schwarz MI, Brown KR, Cherniack RM: Predicting survival in idiopathic pulmonary fibrosis: scoring system and survival model. Am J Respir Crit Care Med 2001;164:1171-1181.

$>7$ Lama VN, Flaherty KR, Toews GB, et al: Prognostic value of desaturation during a 6-minute walk test in idiopathic interstitial pneumonia. Am J Respir Crit Care Med 2003;168:1084-1090.

$>8$ Flaherty KR, Andrei AC, Murray S, et al: Idiopathic pulmonary fibrosis: prognostic value of changes in physiology and six-minutewalk test. Am J Respir Crit Care Med 2006; 174:803-809.

>9 Jezek V, Fucik J, Michaljanic A, Jezkova L: The prognostic significance of functional tests in cryptogenic fibrosing alveolitis. Bull Eur Physiopathol Respir 1980;16:711-720.

-10 Lettieri CJ, Nathan SD, Barnett SD, Ahmad S, Shorr AF: Prevalence and outcomes of pulmonary arterial hypertension in advanced idiopathic pulmonary fibrosis. Chest 2006; 129:746-752.

>11 Nadrous HF, Pellikka PA, Krowka MJ, et al: Pulmonary hypertension in patients with idiopathic pulmonary fibrosis. Chest 2005; 128:2393-2399.

12 Hamada K, Nagai S, Tanaka S, et al: Significance of pulmonary arterial pressure and diffusion capacity of the lung as prognosticator in patients with idiopathic pulmonary fibrosis. Chest 2007;131:650-656.

13 Gläser S, Noga O, Koch B, et al: Impact of pulmonary hypertension on gas exchange and exercise capacity in patients with pulmonary fibrosis. Respir Med 2009; 103:317324.
14 Task Force for Diagnosis and Treatment of Pulmonary Hypertension of European Society of Cardiology (ESC); European Respiratory Society (ERS); International Society of Heart and Lung Transplantation (ISHLT), Galiè N, Hoeper MM, Humbert M, et al: Guidelines for the diagnosis and treatment of pulmonary hypertension. Eur Respir J 2009;34:1219-1263.

15 Arcasoy SM, Christie JD, Ferrari VA, et al: Echocardiographic assessment of pulmonary hypertension in patients with advanced lung disease. Am J Respir Crit Care Med 2003;167:735-740.

16 Nathan SD, Shlobin OA, Barnett SD, et al: Right ventricular systolic pressure by echocardiography as a predictor of pulmonary hypertension in idiopathic pulmonary fibrosis. Respir Med 2008;102:1305-1310.

17 Weitzenblum E, Ehrhart M, Rasaholinjanahary J, Hirth C: Pulmonary hemodynamics in idiopathic pulmonary fibrosis and other interstitial pulmonary diseases. Respiration 1983;44:118-127.

18 Hawrylkiewicz I, Izdebska-Makosa Z, Grebska E, et al: Pulmonary haemodynamics at rest and on exercise in patients with idiopathic pulmonary fibrosis. Bull Eur Physiopathol Respir 1982;18:403-410.

19 Shorr AF, Wainright JL, Cors CS, Lettieri CJ, Nathan SD: Pulmonary hypertension in patients with pulmonary fibrosis awaiting lung transplant. Eur Respir J 2007;30:715-721.

20 Lederer DJ, Arcasoy SM, Wilt JS, D’Ovidio F, Sonett JR, Kawut SM: Six-minute-walk distance predicts waiting list survival in idiopathic pulmonary fibrosis. Am J Respir Crit Care Med 2006;174:659-664.

21 Modrykamien AM, Gudavalli R, McCarthy K, Parambil J: Echocardiography, 6-minute walk distance, and distance-saturation product as predictors of pulmonary arterial hypertension in idiopathic pulmonary fibrosis. Respir Care 2010;55:584-588.

22 Papakosta D, Dimadi M, Stagaki E, et al, on behalf of the Hellenic ILD group: Prevalence of pulmonary hypertension in patients with idiopathic pulmonary fibrosis; a multicenter study. Eur Respir J 2007;30:P818.

23 Nathan SD, Shlobin OA, Ahmad S, Urbanek S, Barnett SD: Pulmonary hypertension and pulmonary function testing in idiopathic pulmonary fibrosis. Chest 2007;131:657663.

24 Nathan SD, Shlobin OA, Ahmad S, et al: Serial development of pulmonary hypertension in patients with idiopathic pulmonary fibrosis. Respiration 2008;76:288-294.

25 Nathan SD, Noble PW, Tuder RM: Idiopathic pulmonary fibrosis and pulmonary hypertension: connecting the dots. Am J Respir Crit Care Med 2007; 175:875-880.
26 Ryu JH, Krowka MJ, Pellikka PA, Swanson KL, McGoon MD: Pulmonary hypertension in patients with interstitial lung diseases. Mayo Clin Proc 2007;82:342-350.

-27 Renzoni EA, Walsh DA, Salmon M, et al: Interstitial vascularity in fibrosing alveolitis. Am J Respir Crit Care Med 2003;167:438443.

$>28$ Kim KH, Maldonado F, Ryu JH, et al: Iron deposition and increased alveolar septal capillary density in nonfibrotic lung tissue are associated with pulmonary hypertension in idiopathic pulmonary fibrosis. Respir Res 2010;11:37.

29 Turner-Warwick M: Precapillary systemicpulmonary anastomoses. Thorax 1963;18: 225-237.

-30 Ebina M, Shimizukawa M, Shibata N, et al: Heterogeneous increase in cd34-positive alveolar capillaries in idiopathic pulmonary fibrosis. Am J Respir Crit Care Med 2004; 169:1203-1208.

-31 Magro CM, Waldman WJ, Knight DA, et al: Idiopathic pulmonary fibrosis related to endothelial injury and antiendothelial cell antibodies. Hum Immunol 2006;67:284-297.

32 Antoniou KM, Tzouvelekis A, Alexandrakis MG, et al: Different angiogenic activity in pulmonary sarcoidosis and idiopathic pulmonary fibrosis. Chest 2006;130:982-988.

33 Gagermeier J, Dauber J, Yousem S, Gibson K, Kaminski N: Abnormal vascular phenotypes in patients with idiopathic pulmonary fibrosis and secondary pulmonary hypertension. Chest 2005;128(6 suppl):601S.

34 Naeije R, Barberà JA: Pulmonary hypertension associated with COPD. Crit Care 2001; 5:286-289.

35 Trakada G, Nikolaou E, Pouli A, et al: Endothelin-1 levels in interstitial lung disease patients during sleep. Sleep Breath 2003;7:111118 .

36 Corte TJ, Wort SJ, Wells AU: Pulmonary hypertension in idiopathic pulmonary fibrosis: a review. Sarcoidosis Vasc Diffuse Lung Dis 2009;26:7-19.

-37 Pouwels-Fry S, Pouwels S, Fournier C, et al: Effects of oxygen on exercise-induced increase of pulmonary arterial pressure in idiopathic pulmonary fibrosis. Sarcoidosis Vasc Diffuse Lung Dis 2008;25:133-139.

38 Patel NM, Lederer DJ, Borczuk AC, Kawut SM: Pulmonary hypertension in idiopathic pulmonary fibrosis. Chest 2007;132:9981006.

39 Charbeneau RP, Peters-Golden M: Eicosanoids: mediators and therapeutic targets in fibrotic lung disease. Clin Sci (Lond) 2005; 108:479-491. 
-40 Wright L, Tuder RM, Wang J, Cool CD, Lepley RA, Voelkel NF: 5-Lipoxygenase and 5-lipoxygenase activating protein (FLAP) immunoreactivity in lungs from patients with primary pulmonary hypertension. Am J Respir Crit Care Med 1998;157:219-229.

-41 Tuder RM, Cool CD, Geraci MW, et al: Prostacyclin synthase expression is decreased in lungs from patients with severe pulmonary hypertension. Am J Respir Crit Care Med 1998;159:1925-1932.

-42 Yanagisawa M, Kurihara H, Kimura S, et al: A novel potent vasoconstrictor peptide produced by vascular endothelial cells. Nature 1988;332:411-415.

-43 Fonseca C, Abraham D, Renzoni EA: Endothelin in pulmonary fibrosis. Am J Respir Cell Mol Biol 2011;44:1-10.

-44 Giaid A, Michel RP, Stewart DJ, Sheppard M, Corrin B, Hamid Q: Expression of endothelin-1 in lungs of patients with cryptogenic fibrosing alveolitis. Lancet 1993;341:15501554.

-45 Uguccioni M, Pulsatelli L, Grigolo B, et al: Endothelin-1 in idiopathic pulmonary fibrosis. J Clin Pathol 1995;48:330-334.

-46 Reichenberger F, Schauer J, Kellner K, Sack U, Stiehl P, Winkler J: Different expression of endothelin in the bronchoalveolar lavage in patients with pulmonary diseases. Lung 2001;179:163-174.

47 Saleh D, Furukawa K, Tsao MS, et al: Elevated expression of endothelin-1 and endothelin-converting enzyme-1 in idiopathic pulmonary fibrosis: possible involvement of proinflammatory cytokines. Am J Respir Cell Mol Biol 1997;16:187-193.

48 Barst RJ, McGoon M, Torbicki A, et al: Diagnosis and differential assessment of pulmonary arterial hypertension. J Am Coll Cardiol 2004;43:40S-47S.

49 Mermigkis C, Stagaki E, Tryfon S, et al: How common is sleep-disordered breathing in patients with idiopathic pulmonary fibrosis? Sleep Breath 2010;14:387-390.

-50 Nathan SD, Basavaraj A, Reichner C, et al: Prevalence and impact of coronary artery disease in idiopathic pulmonary fibrosis. Respir Med 2010;104:1035-1041.

- 51 Ng CS, Wells AU, Padley SP: A CT sign of chronic pulmonary arterial hypertension: the ratio of main pulmonary artery to aortic diameter. J Thorac Imaging 1999;14:270278.

- 52 Zisman DA, Karlamangla AS, Ross DJ, et al: High-resolution CT findings do not predict the presence of pulmonary hypertension in advanced idiopathic pulmonary fibrosis. Chest 2007;132:773-779.

53 Resten A, Maitre S, Humbert M, et al: Pulmonary hypertension: $\mathrm{CT}$ of the chest in pulmonary venoocclusive disease. Am J Roentgenol 2004;183:65-70.
4 Todd NW, Lavania S, Park MH, et al: Variable prevalence of pulmonary hypertension in patients with advanced interstitial pneumonia. J Heart Lung Transplant 2010;29: 188-194.

-55 Zisman DA, Ross DJ, Belperio JA, et al: Prediction of pulmonary hypertension in idiopathic pulmonary fibrosis. Respir Med 2007; 101:2153-2159.

56 Zisman DA, Karlamangla AS, Kawut SM, et al: Validation of a method to screen for pulmonary hypertension in advanced idiopathic pulmonary fibrosis. Chest 2008;133:640645.

57 Ghanem MK, Makhlouf HA, Agmy GR, Imam HM, Fouad DA: Evaluation of recently validated non-invasive formula using basic lung functions as new screening tool for pulmonary hypertension in idiopathic pulmonary fibrosis patients. Ann Thorac Med 2009;4:187-196.

58 Cottin V, Le Pavec J, Prévot G, et al: Pulmonary hypertension in patients with combined pulmonary fibrosis and emphysema syndrome. Eur Respir J 2010;35:105-111.

-59 Mejía M, Carrillo G, Rojas-Serrano J, et al: Idiopathic fibrosis and emphysema: decreased survival associated with severe pulmonary arterial hypertension. Chest 2009; 136:10-15.

60 Bouros D: Combined pulmonary fibrosis and emphysema syndrome. Pneumon 2009; 22:128-130.

61 Cottin V, Nunes H, Brillet P, et al: Combined pulmonary fibrosis and emphysema: a distinct underrecognised entity. Eur Respir J 2005;26:586-593.

62 Aduen JF, Zisman DA, Mobin SI, et al: Retrospective study of pulmonary function tests in patients presenting with isolated reduction in single-breath diffusion capacity: implications for the diagnosis of combined obstructive and restrictive lung disease. Mayo Clin Proc 2007;82:48-54.

63 Fell CD, Liu LX, Motika C, et al: The prognostic value of cardiopulmonary exercise testing in idiopathic pulmonary fibrosis. Am J Respir Crit Care Med 2009;179:402-407.

64 Strange C, Highland KB: Pulmonary hypertension in interstitial lung disease. Curr Opin Pulm Med 2005;11:452-455.

65 Ferrazza AM, Martolini D, Valli G, Palange $P$ : Cardiopulmonary exercise testing in the functional and prognostic evaluation of patients with pulmonary diseases. Respiration 2009;77:3-17.

66 Papadopoulos CE, Pitsiou G, Karamitsos $\mathrm{TD}$, et al: Left ventricular diastolic dysfunction in idiopathic pulmonary fibrosis: a tissue Doppler echocardiographic study. Eur Respir J 2008;31:701-706.

67 Kawut SM, O’Shea MK, Bartels MN, Wilt JS, Sonett JR, Arcasoy SM: Exercise testing determines survival in patients with diffuse parenchymal lung disease evaluated for lung transplantation. Respir Med 2005;99:14311439.
68 Boutou AK, Pitsiou G, Trigonis I, et al: Exercise capacity in idiopathic pulmonary fibrosis: the effect of pulmonary hypertension. Respirology 2011;16:451-458.

69 Schiller NB: Pulmonary artery pressure estimation by Doppler and two-dimensional echocardiography. Cardiol Clin 1990;8:277287.

70 Swanson KL, Utz JP, Krowka MJ: Doppler echocardiography-right heart catheterization relationships in patients with idiopathic pulmonary fibrosis and suspected pulmonary hypertension. Med Sci Monit 2008; 14:CR177-CR182.

71 Hoeper MM, Lee SH, Voswinckel R, et al: Complications of right heart catheterization procedures in patients with pulmonary hypertension in experienced centers. J Am Coll Cardiol 2006;48:2546-2552.

72 Behr J, Ryu JH: Pulmonary hypertension in interstitial lung disease. Eur Respir J 2008; 31:1357-1367.

73 Yap LB, Mukrejee D, Timms PM, Ashrafian H, Coghlan JG: Natriuretic peptides, respiratory disease, and the right heart. Chest 2004;126:1330-1336.

74 Leuchte $\mathrm{HH}$, Neurohr C, Baumgartner RA, et al: Brain natriuretic peptide and exercise capacity in lung fibrosis and pulmonary hypertension. Am J Respir Crit Care Med 2004; 170:360-365.

75 Leuchte HH, Baumgartner RA, El-Nounou $\mathrm{ME}$, et al: Brain natriuretic peptide is a prognostic parameter in chronic lung disease. Am J Respir Crit Care Med 2006;173:744750 .

76 Leuchte HH, El-Nounou ME, Tuerpe JC, et al: N-terminal pro-brain natriuretic peptide and renal insufficiency as predictors of mortality in pulmonary hypertension. Chest 2007;131:402-409.

-77 Wieshammer S, Dreyhaupt J, Basler B, Marsovszky E: NT-proBNP for pulmonologists: not only a rule-out test for systolic heart failure but also a global marker of heart disease. Respiration 2009;77:370-380.

78 Song JW, Song JK, Kim DS: Echocardiography and brain natriuretic peptide as prognostic indicators in idiopathic pulmonary fibrosis. Respir Med 2009;103:180-186.

-79 Corte TJ, Wort SJ, Gatzoulis MA, Engel R, Giannakoulas G, Macdonald PM, Wells AU: Elevated brain natriuretic peptide predicts mortality in interstitial lung disease. Eur Respir J 2010;36:819-825.

-80 Swigris JJ, Swick J, Wamboldt FS, et al: Heart rate recovery after 6 -min walk test predicts survival in patients with idiopathic pulmonary fibrosis. Chest 2009;136:841-848.

81 Corte TJ, Wort SJ, Gatzoulis MA, et al: Pulmonary vascular resistance predicts early mortality in patients with diffuse fibrotic lung disease and suspected pulmonary hypertension. Thorax 2009;64:883-888. 
82 Pitsiou G, Papadopoulos CE, Karvounis HI, et al: Utility of tissue Doppler imaging in predicting outcome in patients with idiopathic pulmonary fibrosis. Hellenic J Cardiol 2007;48:143-151.

83 Bando K, Keenan RJ, Paradis IL, et al: Impact of pulmonary hypertension on outcome after single-lung transplantation. Ann Thorac Surg 1994;58:1336-1342.

84 Harari S, Simonneau G, De Juli E, et al: Prognostic value of pulmonary hypertension in patients with chronic interstitial lung disease referred for lung or heart-lung transplantation. J Heart Lung Transplant 1997;16: 460-463.

-85 Huerd SS, Hodges TN, Grover FL, et al: Secondary pulmonary hypertension does not adversely affect outcome after single lung transplantation. J Thorac Cardiovasc Surg 2000;119:458-465.

86 Fitton TP, Kosowski TR, Barreiro CJ, et al: Impact of secondary pulmonary hypertension on lung transplant outcome. J Heart Lung Transplant 2005;24:1254-1259.

87 Whelan TP, Dunitz JM, Kelly RF, et al: Effect of preoperative pulmonary artery pressure on early survival after lung transplantation for idiopathic pulmonary fibrosis. J Heart Lung Transplant 2005;24:1269-1274.

88 Fell CD, Martinez FJ: The impact of pulmonary arterial hypertension on idiopathic pulmonary fibrosis. Chest 2007;131:641643.

89 Humbert M, Sitbon O, Simonneau G: Treatment of pulmonary arterial hypertension. $\mathrm{N}$ Engl J Med 2004;351:1425-1436.

$\$ 90$ McLaughlin VV, McGoon MD: Pulmonary arterial hypertension. Circulation 2006;114: 1417-1431.

91 Olschewski H, Ghofrani HA, Walmrath D, et al: Inhaled prostacyclin and iloprost in severe pulmonary hypertension secondary to lung fibrosis. Am J Respir Crit Care Med 1999;160:600-607.
92 Strange C, Bolster M, Mazur J, et al: Hemodynamic effects of epoprostenol in patients with systemic sclerosis and pulmonary hypertension. Chest 2000;118:1077-1082.

$\$ 93$ Ghofrani HA, Wiedemann R, Rose F, et al: Sildenafil for treatment of lung fibrosis and pulmonary hypertension: a randomised controlled trial. Lancet 2002;360:895-900.

$\$ 94$ Saggar R, Shapiro SS, Ross DJ, et al: Treprostinil to reverse pulmonary hypertension associated with idiopathic pulmonary fibrosis as a bridge to single-lung transplantation. J Heart Lung Transplant 2009;28: 964-967.

95 Yung GL, Kriett JM, Jamieson SW, et al: Outpatient inhaled nitric oxide in a patient with idiopathic pulmonary fibrosis: a bridge to lung transplantation. J Heart Lung Transplant 2001;20:1224-1227.

$\$ 66$ Galie N, Ghofrani HA, Torbicki A, et al: Sildenafil citrate therapy for pulmonary arterial hypertension. N Engl J Med 2005;353: 2148-2157.

-97 Collard HR, Anstrom KJ, Schwarz MI, Zisman DA: Sildenafil improves walk distance in idiopathic pulmonary fibrosis. Chest 2007;131:897-899.

98 Madden BP, Sheth A, Wilde M, Ong YE: Does Sildenafil produce a sustained benefit in patients with pulmonary hypertension associated with parenchymal lung and cardiac disease? Vascul Pharmacol 2007;47: 184-188.

99 Chapman TH, Wilde M, Sheth A, Madden BP: Sildenafil therapy in secondary pulmonary hypertension: is there benefit in prolonged use? Vascul Pharmacol 2009;51:9095.

100 The Idiopathic Pulmonary Fibrosis Clinical Research Network: A controlled trial of sildenafil in advanced idiopathic pulmonary fibrosis. N Engl J Med 2010;363:620628.
01 Channick RN, Simonneau G, Sitbon O, et al: Effects of the dual endothelin-receptor antagonist bosentan in patients with pulmonary hypertension: a randomized placebo-controlled study. Lancet 2001;358:11191123.

102 Rubin LJ, Badesch DB, Barst RJ, et al: Bosentan therapy for pulmonary arterial hypertension. N Engl J Med 2002;346:896903.

103 Günther A, Enke B, Markart P, et al: Safety and tolerability of bosentan in idiopathic pulmonary fibrosis: an open label study. Eur Respir J 2007;29:713-719.

104 King TE Jr, Behr J, Brown KK, et al: BUILD-1: a randomized placebo-controlled trial of bosentan in idiopathic pulmonary fibrosis. Am J Respir Crit Care Med 2008; 177:75-81.

105 Raghu G, King TE Jr, Behr J, et al: Quality of life and dyspnoea in patients treated with bosentan for idiopathic pulmonary fibrosis (BUILD-1). Eur Respir J 2010;35:118-123.

106 Orens JB, Estenne M, Arcasoy S, et al: International guidelines for the selection of lung transplant candidates: 2006 update - a consensus report from the Pulmonary Scientific Council of the International Society for Heart and Lung Transplantation. J Heart Lung Transplant 2006;25:745-755.

107 Conte JV, Borja MJ, Patel CB, Yang SC, Jhaveri RM, Orens JB: Lung transplantation for primary and secondary pulmonary hypertension. Ann Thorac Surg 2001;72: 1673-1679.

108 Christie JD, Edwards LB, Aurora P, et al: The Registry of the International Society for Heart and Lung Transplantation: Twenty-sixth Official Adult Lung and HeartLung Transplantation Report - 2009. J Heart Lung Transplant 2009;28:1031-1049. 